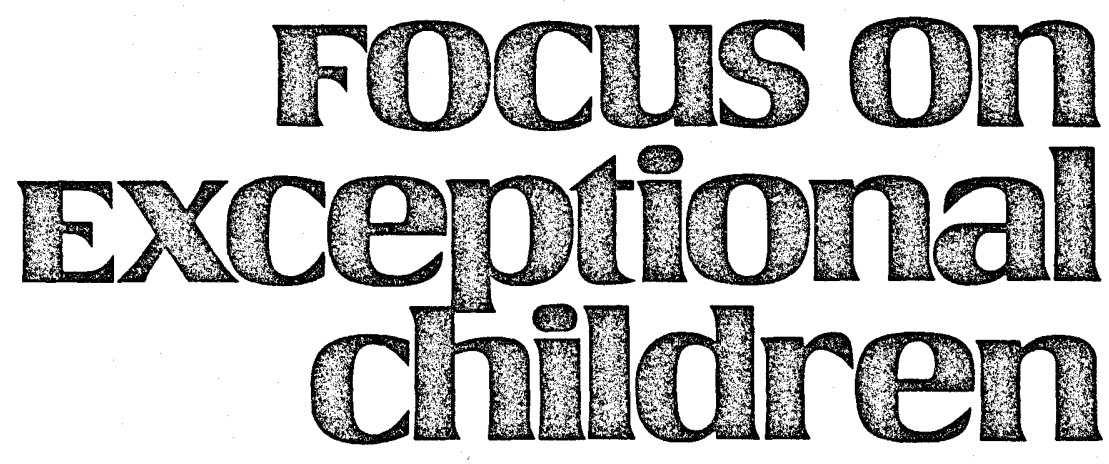

\title{
Effective Instruction with Microcomputers: Promises, Practices, and Preliminary Findings
}

\author{
Edwin S. Ellis and Edward J. Sabornie
}

In a recent survey, Mokros and Russell (1986) reported that $88 \%$ of the schools surveyed were using microcomputers with learning disabled or behaviorally disordered students. Maddux (1984) reported that 160,000 microcomputers were being used in special education programs. In light of the ever increasing role that microcomputers play in education of mildly handicapped students, the need for clarification of effective instruction with microcomputers is considerable. Though severely lacking in empirically based articles that investigate authenticity, the literature contains many promises related to the advantages and potentials of using microcomputers. The intent of this article is to provide special educators with an overview of the promises of microcomputers and review the extent to which they have been addressed, in relation to effective instruction, by research. On the whole, the studies reflect highly encouraging results, but much research is needed in this area.

\section{PROMISE 1: MICROCOMPUTERS INCREASE MOTIVATION TO LEARN}

Perhaps the most common promise of microcomputer applications is associated with its ability to motivate students (e.g., Arms, 1984; Bell, 1983; Furst, 1983; Gray, 1984; Tyler, 1983). Motivational aspects are discussed below from the perspective of primary reinforcers (it is intrinsically motivating to learn when operating the microcomputer) and from the perspective of secondary motivators-using opportunities to interact with the microcomputer as a reward.

\section{Use as a Primary Reinforcer}

How motivating is interaction with the computer in an academic setting? Although we found few studies that directly measured motivation, one indicator is whether students are on task when given opportunities to interact with the computer. In a recent investigation that involved surveys, observations, and interviews with teachers and administrators in public schools, Reith (1986) reported a number of interesting findings. First, in classes with computer-based instruction, students spent only $24.1 \%$ of their time working at the computer. In fact, students engaged in paper-and-pencil activities more often in computeruse classrooms than in non-computer classes. The extra time created by using the computer as the instructor appeared to be invested in paper-and-pencil activities-an activity found by Reith and Frick (1983) to increase the likelihood of off-task behavior by seven times.

Dr. Ellis and Dr. Sabornie are Assistant Professors in the Department of Educational Psychology, University of South Carolina. 
Yet in those computer-use classes, students were more likely to be engaged in learning than were their counterparts in non-computer classes. Other educators (e.g., MacArthur, Haynes, \& Malouf, 1985; MacArthur, Haynes, Malouf, \& Harris, 1986) have reported similar findings of on-task behavior of mildly handicapped students during computer-assisted instruction (CAI). An important issue is to determine whether computers remain motivational as the novelty wears off (Clark, 1983). Limited evidence offered by Romanczyk (1986) and Chiang (1986) indicated that novelty is a key factor in the motivation dimension. Romanczyk reported that when examining the generalization effects of CAI math instruction with learning disabled children, initial positive effects were found to be transitory and appeared to be tied to the novelty effects. During a study investigating the effects of a drill-and-practice program designed to reinforce knowledge of multiplication tables, Chiang observed that the software, Treasure Hunt, produced high levels of initial motivation, but students eventually became disillusioned and even resented the features designed to enhance motivation.

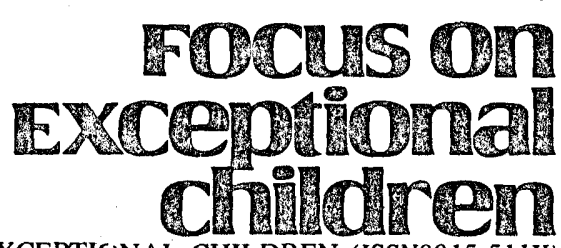

FOCUS ON EXCEPTIONAL CHILDREN (ISSN0015-511X) (USPS 203-360) is published monthly except June, July, and August as a service to teachers, special educators, curriculum specialists, administrators, and those concerned with the special education of exceptional children. This journal is abstracted and indexed in Exceptional Child Education Resources, and is also available in microform from Xerox University Microfilm, Ann Arbor, Michigan. Subscription rates: Individuals, $\$ 24$ per year; institutions, $\$ 30$ per year. Copyright 101986 , Love Publishing Company. All rights reserved. Reproduction in whole or part without written permission is prohibited. Printed in the United States of America. Second class postage is paid at Denver, Colorado.

POSTMASTER: Send address changes to:

Love Publishing Company

Executive and Editorial Office

1777 South Bellaire Street

Denver, Colorado 80222

Telephone (303) 757-2579

EDITORIAL BOARD

$\begin{array}{cc}\text { Edward L. Meyen } & \text { Glenn A. Vergason } \\ \text { University of Kansas } & \text { Georgia State University } \\ \text { Richard J. Whelan } & \end{array}$

University of Kansas Medical Center
Stanley F. Love
Carolyn Acheson
Publisher

Lieber and Semmel (1986) reported similar observations in that students had a high percentage of on-task behavior across special education and mainstreamed settings, but there does seem to be an interaction effect with social variables. For example, Semmel reported that when peers were present, learning handicapped students were more frequently off-task. Studies reported by Romanczyk (1986) suggested that severely emotionally disturbed and autistic students appear to learn effectively with the computer because they do not have to interact with others. Self-stimulatory and actingout behaviors were observed to virtually disappear when the severely disordered students interacted with the computer.

An issue related to motivation is the perceived need to use entertaining flashing lights, arcade-like sounds, and fancy graphics to maintain the students' motivation while learning. Although these features are used to enhance motivation (Chaffin, Maxwell, \& Thompson, 1982; Malone, 1981), LeBlanc, Hoko, Aangeenbrug, and Etzel (1985) and Christensen and Gerber (1986) noted that many software programs incorporate these features with little or no concern for the appropriateness of the technique. They suggested that such salient stimuli can interfere with learning because of their distracting features.

In a review of the history of CAI as related to its use with mainframe computers, Torgesen (1986a) concluded that programs incorporating effective management routines had consistently more positive effects than those relying heavily on graphics, sound effects, or animation. Following a CAI study, Chiang (1986) concluded that numerous extraneous features and themes (e.g., treasure hunt, meteor shooting) associated with arcade-like games may not be as effective as a simple drill-and-practice program. Christensen and Gerber (1986) also found that when practicing addition through CAI, learning disabled students using a plain CAI performed significantly better than students who trained using the arcade-like game format CAI. Moreover, students using the plain CAI practiced the problems more.

Malouf (1985) provided one of the few studies specifically designed to evaluate the importance of computer games in relation to motivation. The study used sixth, seventh, and eighth grade learning disabled students with varying levels of initial motivation to compare a drill-and-practice computer game with another program that operated identically but contained minimal game features. Results of the study indicated that the program employing game features produced higher continuing motivation than the non-game program with LD students whose motivation was initially low. In contrast, no differences in continuing motivation were observed with students who initially had high motivation. 
The study provided limited evidence that educators' concerns about the distracting features associated with arcadelike games programs may be unfounded, but even tentative conclusions concerning this issue would be premature considering the lack of empirical investigation in this area. Regardless of the interference effects that may accompany some CAI, any form of academic engagement may be welcome for students who are extremely reluctant learners.

\section{Use as a Secondary Reinforcer}

Many special education teachers use the microcomputer as a reinforcer to motivate students to complete tasks unrelated to the computer (Reith, 1986). Although few studies have formally addressed the relative salience of the microcomputer as a back-up motivator, this particular application may not be the most desirable for two reasons. First, although it admittedly is a motivator for increasing performance at other tasks, it is also a great time thief when used in this manner (Komoshi, 1981). Time playing entertaining arcade-like games is time taken away from more direct forms of instruction. Some instructors use academic drill-and-practice programs, instead of entertaining games, as reinforcers-the argument being that the student is working on academic-related activities. Many teachers, however, simply direct a student to choose from a collection of software drill-and-practice programs those that he or she wishes to use. Little systematic, purposeful planning for review and practice of specific skills takes place in these instances.

The second area of concern involves use of extrinsics such as free time for game playing. Several educators have cautioned that nonjudicial use of extrinsic reinforcers can foster external locus of control and dependency-behaviors that run counter to facilitating independence (Adleman \& Taylor, 1983; Close, Irvin, Taylor, \& Agosta, 1981; Deci, 1975; Ellis, 1986; Ellis, Lenz, \& Sabornie, in press; Licht \& Kistner, 1986; Schumaker, Deshler, \& Ellis, 1986). Other motivational techniques, however, have been found to be quite effective. These include: (a) providing a high number of success experiences for the students by requiring frequent responses that will assure correct answers (Stevens \& Rosenshine, 1981; Anderson, Evertson, \& Brophy, 1979; Good \& Grouws, 1979); (b) having students chart their prior progress and before each new practice attempt (Adams, Archer, Ellis, \& Moorehead, in press); and (c) having students plot a point predicting performance on the next practice attempt (Tollefson, Tracy, Johnson, Buenning, Farmer, \& Barke, 1982; Tollefson, Tracy, \& Johnson, 1982.) The instructional time and monetary cost in using these procedures is negligible, plus they foster independence of action.

\section{PROMISE 2: MICROCOMPUTERS INCREASE SELF-CONCEPT}

Increased self-concept is an often touted advantage of computer-assisted instruction (Furst, 1983; Schiffman, Tobin, \& Buchanan, 1982). A search in the available literature does not reveal any studies that have specifically addressed the claim that interactions with the microcomputer using educational software will increase self-concept. Many educators have maintained, however, that one of the most appropriate ways to improve self-concept is to increase the student's level of success and to increase the amount of learning that takes place (Adams et al., in press). A key to effective instruction is the instructor's ability to facilitate students' academic engaged time (Adams et al., in press; Anderson, Evertson, \& Brophy, 1979; Good \& Grouws, 1979; Stevens \& Rosenshine, 1981) - that is, not just to produce on-task behavior but, rather, to manage students' behavior so that they frequently produce a maximum number of academic-related correct reponses.

This line of logic can lead one to conclude that the more the students make correct academic responses, the greater is the probability that self-concept will be enhanced. Studies using the microcomputer have demonstrated clearly that some programs are able to facilitate academic engaged time with marked effectiveness (e.g., MacArthur, Haynes, Malouf, \& Harris, 1986). These studies will be reviewed throughout the remainder of the article.

\section{PROMISE 3: LOGO WORKS WONDERS}

A number of writers have noted that LOGO, a simple programming language, has great potential for helping learning disabled and other handicapped students (Abelson \& di Sessa, 1982; Gray, 1984; Maddux, 1984; Schiffman, Tobin, \& Buchanan, 1982; Weir, 1982). For example, Weir and Watt (1981) indicated that LOGO programming experiences have the potential to improve fine-motor skills, increase short-term memory, help students learn to use feedback more effectively, move from concrete to more abstract levels of thinking, and through successes associated with the experiences, possibly lead to improved attitudes about learning and improved self-confidence. Torgesen (1986b) noted that only ambiguous, anecdotal evidence is offered to support these claims; although it cannot be argued that LOGO experi- 
ences do not produce these effects, little empirical data have been provided to substantiate any of the promises made by LOGO enthusiasts.

\section{PROMISE 4: MICROCOMPUTER INSTRUCTION CAN BE SUPERIOR TO TRADITIONAL INSTRUCTIONAL PROCEDURES}

A promise that frequently appears in the literature is that microcomputers can be as (or more) effective as traditional teacher-assisted (TA) instructional procedures (Guess, 1981; Hoffman, 1982; Kulik, Kulik, \& Cohen, 1980; Magidson, 1978). A number of educators (e.g., Chiang, 1986; Lieber \& Semmel, 1985; Romanczyk, 1986) have noted that research has not clearly validated the relative effectiveness of CAI as opposed to TA instruction. A few studies have begun to address this promise, but the claim is too broad to lend itself to precise empirical investigation (Clark, 1983), as instruction consists of multidimensional variables that are difficult to control. Of the few studies designed to compare CAI with TA, findings are ambiguous and do not allow even tentative conclusions concerning the superiority of CAI.

For example, Trifiletti, Frith, and Armstrong (1984) compared a computer-assisted approach with the teacher-guided approach used in a resource room setting for teaching basic math skills to 21 learning disabled students. They reported that the $12 \mathrm{LD}$ students who had received CAI math instruction for 40 minutes a day over a 4-month period learned almost twice as many new math skills as their 9 counterparts in the resource setting room. Although these results are impressive, it is unclear whether they reflect more on the effectiveness of the CAI or the ineffectiveness of the LD resource room teacher in the comparison group (Torgesen, 1986a).

McDermott and Watkins (1983) offer contrasting data. They compared CAI-based math and spelling programs with conventional remedial instruction over a period of one school year. Findings reflected essentially no difference between the $129 \mathrm{LD}$ students in the conventional group and the 38 LD students receiving math CAI and 41 LD students receiving spelling CAI. Further, Fitzgerald, Fick, and Milich (1986), using 9 elementary students characterized by their teachers as having attention deficits, compared CAI designed to teach spelling, a traditional "write-and-check" form of instruction, and a no-practice condition. Students received the instruction over a period of 5 weeks, learning five new words per week. The no-practice condition naturally was found to be inferior, but no differences were found between the CAI and the TA approaches. Fitzgerald et al. concluded that CAI was equal or superior to the traditional method. Even so, learning 15 new words in 5 weeks does not suggest highly efficient instruction in either condition. Other investigators, too, have found no differences between CAI and TA (e.g., Carman \& Kosberg, 1982; Kleiman, Humphrey, \& Lindsay, 1983).

Some studies have attempted to control for the multidimensional aspects of instructional design by carefully attempting to parallel control group instruction with activities used in the CAI, but results are still equivocal. Haynes, Kapinus, Malouf, and MacArthur (1984) examined the effects of CAI, paired with metacognitive activities (e.g., predicting how many would be correct on the next test) as compared to a TA practice using a paper-and-pencil activity format that closely paralleled spelling, definition, and correct usage of words in sentences. Results revealed no significant differences among the two conditions on either immediate retention or on the amount of time required to practice the new knowledge. Varnhagen and Gerber's (1984) finding that paper-and-pencil activities produced superior performance offers additional evidence in support of TA over CAI. In contrast, Romanczyk (1986) reported that in three studies that matched the conditions on a number of variables (e.g., pacing, difficulty level, degree of interchange, reinforcement) and involved teaching mathematics to neurologically impaired, emotionally disturbed, and LD children, CAI was found to be as effective as teacher-assisted instruction with many of the students.

Torgesen (1986a, 1986b) noted that a relevant dimension appears to be not so much whether the computer or the teacher delivers the instruction but, rather, the extent to which either uses procedures based on mastery learning in which instruction is carefully sequenced and integrated and objectives are well defined and based on established algorithms for making instructional decisions (e.g., determining next instructional procedure based on students' speed and accuracy when performing the skill). Conclusions as such are logically consistent with the effective TA instruction findings (Brophy \& Good, 1984; Engelmann \& Carnine, 1982; Gersten, Woodward, \& Darch, 1986; Morsink, Soar, Soar, \& Thomas, 1986; Samuels, 1986; Stevens \& Rosenshine, 1981), but clarification is needed in how to design programs so that these principles are effectively employed by CAI.

Further, some CAI may be more appropriate for different content and skill areas [e.g., learning math and spelling facts versus developing reading comprehension or problem- 
solving strategies (Torgesen, 1986b)], and effectiveness may be more related to the level of learning the student is currently performing [e.g., acquiring new skills versus acquiring automaticity of previously learned skills (Carlson \& Silverman, 1986; Torgesen, 1986b)], and may be related to the form CAI employed (e.g., tutoring, drill-and-practice, simulations). The following promises address these more specific concerns.

\section{PROMISE 5: MICROCOMPUTERS CAN BE USED AS TUTORS FOR INSTRUCTING NEW SKILLS OR KNOWLEDGE}

Although it remains unclear as to whether CAI is as effective or superior in comparison to TA as a general issue, an important area to clarify is how effective $\mathrm{CAI}$ is in teaching new skills or knowledge, regardless of how it compares to TA. Carlson and Silverman (1986) noted that current software is either inappropriate or only marginally helpful in the acquisition of new skills or knowledge. Educators should not over-generalize such statements to believe that CAI is not, or cannot, be effective as a tutor. Existing popular software is more the brunt of that criticism.

Few studies have investigated the role of microcomputers when used as a true tutor of new skills or content, but limited evidence suggests that the microcomputer can be quite effective in teaching knowledge and skills across a variety of domains. The following studies illustrate that, at least to some extent, microcomputers can be effective in providing direct instruction in concepts, processes, and problem solving. Although the primary intent of these studies was not to establish their effectiveness in the various domains, they effectively serve this purpose.

\section{Direct Instruction of New Concepts}

Johnson, Carnine, and Gersten (1986) compared two methods of CAI designed to teach vocabulary to mildly handicapped adolescents. The CAI differed in the magnitude of teaching sets offered within a given lesson and the manner in which cumulative review was provided. Both taught the same 50 words and definitions to 24 mildly handicapped students who had been divided randomly into one condition or the other. The program containing the small teaching set presented, in a single set, no more than three new words in conjunction with seven practice words that the student had previously learned. The student had to meet a mastery criterion on each word before the word was removed. The program containing the large teaching set included 25 new words per set; students were able to choose between one of four presentation options: (a) the word was displayed, along with its definition and one sample sentence using the word; (b) a multiple-choice quiz format; (c) an exercise displaying a correct definition, and the student had to spell the correct missing word to complete a sentence; or (d) an arcade-like game in which the student matched words to correct definitions.

To evaluate the effects of the CAI, measures included time to mastery and pre/post test scores on a 50-item multiple-choice test. In addition, transfer mearsures were taken by an orally administered objective test on the vocabulary words and on a comprehension test that required knowledge of the vocabulary word meanings. Results on the time to mastery measures indicated that the small-set group learned the set of 50 vocabulary words in significantly less time than the large-set group. The small-set group required an average of 7.6 sessions to master the words, whereas the large-set group required a mean of 9.1 sessions. No significant differences were found on the other measures. Results tentatively suggest that information, when presented in small clusters of new information and paired with about twice as much previously learned material, can be an effective way to present new information. More notably, the study illustrates that CAI can be used as an effective tutor in the instruction of concepts.

\section{Direct Instruction of a New Multi-Step Process}

A process is a skill that involves application of a number of steps to solve a problem-e.g., reducing fractions, counting coins, writing an enumerative paragraph (Adams et al., in press). A study by Collins, Carnine, and Gersten (in press) demonstrated that the processes associated with reasoning skills could be successfully taught using a microcomputer as a tutor. The primary intent of the study was to clarify whether "elaborated correction" procedures (detailed corrective feedback, plus modeling steps as necessary to obtain students' correct response) integrated into CAI was more or less effective than "basic corrections" (telling the student that he/she was correct or incorrect and then providing the correct answer if incorrect) when teaching students a new process. The investigation used two versions of a tutoring program designed to teach students to draw conclusions from two statements of evidence and to determine whether a two-statement argument was logical (Engelmann, Carnine, \& Collins, in press). One of the tutoring programs contained the elaborated form of feedback; the other used the 
basic corrections form. The Test of Formal Logic (Collins, 1984) was adapted for use as pre, post, and maintenance test measures. Part of the test evaluated acquisition of the logic skills when constructing and analyzing syllogistic arguments similar to those found in the practice exercises. The remainder of the test evaluated the students' ability to generalize the new skills to similar analytic tasks but was presented in prose paragraph form.

Although the finding that the 17 mildly handicapped students who used the elaborated feedback version of the software demonstrated significantly greater skill acquisition and transfer than the 17 students who used the basic correction version is not surprising, the study illutrates a significant point: Even though the effectiveness of much of the commercially available software remains largely an empirical question, software that is effective in tutoring a new skill in applying a process can be designed. Moreover, it is possible to design programs employing procedures that provide relatively sophisticated forms of feedback, modeling, and prompting heretofore found only with mainframe computers and live teachers. Which processes lend themselves to CAI and which may be more effectively taught before CAI is introduced, however, remains unclear. The Collins et al. study did not evaluate whether it would have been more effective for the teacher to first provide direct instruction in the logic processes and then allow the computer to follow through with guided practice, as opposed to using only the computer for direct instructional processes.

Evidence from a study by Gleason (1985) suggests that the issue of when to use CAI in problem-solving instruction remains in question. In this investigation CAI was used to teach a step-by-step process for solving math story problems. The process focused on choosing the correct operationmultiplication or division. The CAI employed a direct instructional procedure, providing input on a step-by-step basis. Modeling of each step of the process was used, as well as prompting the students' application of the procedure. When a student erred, the CAI provided rule-based instruction. The study compared the direct instruction CAI program with an instructional procedure using software that focused on semantic guiding (Semantic Calculator). Rather than providing direct instruction of a step-by-step process for solving the story problem, the semantic guiding procedure guided the student through the story by using questions that prompted answers (e.g., "How many?" "What?") to determine how to solve the problem. When students provided incorrect answers to the guiding questions, they were asked to "go back and try again."

Gleason used a 28 -item pre/post test consisting of various word problems requiring all the basic operations. Of the problems, $32 \%$ required the student to transfer the problemsolving skill to novel problems unlike those in the practice lessons. When the 13 students who had been randomly assigned to each group were posttested, results indicated no significant differences between the direct instruction CAI and the semantic guide CAI when the number of correct answers and the time required to take the posttest were analyzed. Observations of student performance indicated that they were ignoring computer prompts that told them what to do next; thus, many students were missing opportunities to learn from their errors. Woodward, Carnine, Gersten, Gleason, Johnson, and Collins (1986) speculated that mildly handicapped students may need more direct instruction from the teacher before using a computer for practice opportunities. Thus, while some software programs may be effective at teaching a skill at the acquisition level, which processes and procedures lend themselves most effectively to this level of learning remains unclear.

\section{Direct Instruction in Problem Solving}

Computers often have been touted as excellent devices for teaching problem solving, but in fact much of the software (e.g., Lemonade, Snooper Troops, Factory, Oregon Trail) that claims to promote problem-solving skills (e.g., planning, sequencing, following directions) only remotely address these skills (Russell, 1986) and may be more appropriately classified as entertainment. Many educators have advocated use of simulations to promote problem-solving skills (Doob, 1972; Greenblat \& Duke, 1975; Budoff, Thormann, \& Gras, 1984), but research comparing simulation instruction with conventional methods has not found the former to be any more effective than the latter. Woodward, Carnine, and Collins (1986) hypothesized that a more effective way to teach problem solving is not to choose between these methods of instruction but, rather, to use both; initially, direct instruction in problem-solving preskills and strategies could be provided, followed by opportunities to practice the new skills while interacting with a simulation. Thus, the simulation activities are used to "enhance rather than replace" problem-solving instruction (p. 14).

Woodward et al. tested this hypothesis using a series of computer simulation activities involving problem solving in health-related areas. Thirty students were randomly divided and assigned to either a conventional or a simulation group. Both groups received the same initial instruction in health-re- 
lated problem-solving skills. Then the conventional group received application and review activities presented by a resource teacher while the other group worked in a computer lab with the CAI simulation activities. The simulation instruction consisted of interacting with Health Ways (Carnine, Lang, \& Wong, 1984), a software program consisting of three phases-initial modeling of the problem-solving routines, guided practice using simulation games, and independent practice with individual feedback using simulation games. Measures consisted of tests designed to assess problem-solving ability (diagnosing health problems, prioritizing them as to their effects on a person's longevity, and prescribing appropriate remedies) on items reinforced by the Health Ways simulation and items taught in the curriculum but not reinforced by the simulation.

Results indicated significant effects on items reinforced by the simulation, and non-significant effects for items not reinforced. Thus, the simulation appeared to be an effective procedure for reviewing material that already had been taught. When the two groups were compared, the simulation group was significantly superior in problem-solving skills.

One of the most exciting promises of the microcomputer is its ability to provide interactive instruction using simulations, but until recently the relative effectiveness of simulations as an instructional technique has been unimpressive. The Woodward et al. study provides important information about how computer simulations can be effectively used to teach problem solving. Although tentative, the results suggest that use of a structured approach to computer simulations (outcomes are specified and controlled) when preceded by direct instruction in problem-solving strategies may be a highly effective approach.

\section{PROMISE 6: MICROCOMPUTERS CAN BE USED FOR DRILL AND PRACTICE TO ATTAIN AUTOMATICITY OF SKILLS}

Drill-and-practice software, one of the most common applications of microcomputer software in special education settings (Reith, 1986; Russell, 1986), has drawn a lot of rhetoric from educators (e.g., Gagne, 1983; Garson, 1983; Hofmeister, 1984; Lepper, 1985; Lesgold, 1983; Russell, 1983; Turkel \& Podell, 1984). Some are very critical. For example, LeBlanc et al. (1985) noted that the primary emphasis of current software is on "teaching what already has been taught rather than upon teaching new skills" (p. 28). They noted that most software typically uses trial-and-error procedures that are responsible for the "educational failure of many children who experience learning difficulties" (p. 28). Carlson and Silverman (1986) criticized most CAI software as little more than electronic flashcard machines. When directed at much of the software commonly used, these negative comments are deserving-especially when the CAI does not closely correlate with skills currently under direct instruction by the teacher.

Unfortunately, the criticisms tend to propagate a negative connotation associated with the concept of computer-assisted "drill and practice," (CAP), as opposed to poorly designed software or poor choices as to which software to use with which students. Torgesen (1986b) noted that drill and practice to attain fluency or automaticity of lower order skills (e.g., word decoding or sight word recognition) often is necessary for higher order skill instruction (e.g., metacomprehension strategies) to be appropriate. Several writers (e.g., Lesgold, 1983; Torgesen \& Young, 1983; Wilkenson, 1983) have maintained that some forms of CAP, as applied to helping students master basic academic skills, constitute a highly desirable application of the microcomputer. A fundamental question is: How effective are microcomputers for facilitating effective practice?

\section{Representative Studies}

Several studies have demonstrated that micocomputers can provide effective practice at increasing mildly handicapped students' word analysis skills. Jones and Torgesen (1985) evaluated Hint and Hunt (Beck \& Roth, 1984), a program designed to provide practice in analyzing medial vowels and vowel combinations by focusing on accuracy and speed in recognizing vowel sounds in words. Pre and post tests were administered to 20 students who, before the intervention, had an average reading rate of 40 words per minute while correctly reading $70 \%$ of the words. The tests required the student to read a word as fast as he or she could after it appeared on the screen. Some of the words from the test were those used during training; others were novel words but contained the same medial vowel and vowel combinations as those addressed by the training.

Results of the drill-and-practice intervention demonstrated that the software can increase decoding fluency. The intervention group demonstrated a $27 \%$ increase in speed of responses on generalized words, while the control group increased its speed by only $4 \%$. The increase in speed was accompanied by an increase in accuracy. The intervention group improved its accuracy by about $20 \%$, whereas the control group demonstrated only a $5 \%$ increase in accuracy. 
Other researchers using other decoding drill-and-practice software have found similar results. For example, Roth and Beck (1984) evaluated the effects of a drill-and-practice program designed to increase decoding by giving the students practice forming many different words from the same sets of beginning and ending word parts. They found that low-achieving fourth graders (i.e., average decoding ability $=1.9$ grade equivalent) increased the speed of vocalization of pseudowords by $25 \%$, resulting in a $17 \%$ increase in sentence reading speed when provided practice using the CAP software. In contrast, the control group's speed at vocalizing pseudowords increased only slightly, while sentence reading speed increased by only $3 \%$. In addition, Spring and Perry (in press) found similar results when students used CAP software for practicing word analysis skills.

Since decoding skills appear to be an area that can benefit from computerized drill and practice, it would seem logical that sight word recognition also would improve using similar programs. Empirical studies suggest that this is indeed the case. With 9 LD students who had few or no reading skills, Cohen and Torgesen (1985) evaluated the effectiveness of a software program designed to teach sight words. The program used pictures to teach the sight words in groups of 10. Two conditions - typing (to make a response, the student had to type the correct word) versus no-typing (a simple one-button response format)-were employed.

Results of speed and accuracy measures following the intervention suggested that students learned a new word for every 6.7 minutes of study in the no-typing condition, as opposed to 8.7 minutes in the typing condition. The practice also had a slight effect on the students' spelling skills. The authors concluded that the program would be appropriate when used as a supplemental practice activity to teach sight words. Rashotte and Torgesen (1985) demonstrated that fluency of sight word reading in prose also can be improved using CAP. They found that word recognition speed could increase via CAP with a program using a repeated readings format.

Chiang (1986) has provided evidence that drill and practice using the microcomputer also can be effective for teaching multiplication facts. Using 4-minute timings and a software program, Treasure Hunt, over a period of 12 days, Chiang demonstrated that students transferred the skills practiced on the computer to paper-and-pencil tasks. As a result of the microcomputer practice, students demonstrated an average gain of 4.7 (girls) and 6.1 (boys) facts per minute on worksheet tasks.

The preceding studies demonstrate that CAI can be applied for effective practice and appear especially appropriate for practicing existing skills to increase automaticity. For the CAI practice to be appropriate, however, teachers should systematically integrate use of the programs with an ongoing instructional plan. Skills practiced with CAI should closely parallel those under TA instruction.

\section{Crossover Instruction}

An important question concerning use of CAP is whether new knowledge or skills are being taught or whether existing skills are being practiced. Hasselbring (1986) investigated whether a basic drill-and-practice routine, typically used for practicing existing skills to attain automaticity, will cross over and have a tutorial effect on learning new skills. He investigated the effects of using CAI to teach reproductive math fact recall processes. The subjects were mildly handicapped students with reconstructive math fact skills (students could construct or calculate correct answers by using a process such as counting on fingers) but lacked knowledge of reproductive math facts (immediate recall of correct answers).

In this investigation the students were provided computerbased drill-and-practice activities in the form of arcade-like games for a 20 - to 30 -day period while working on memorizing answers. Hasselbring used chronometric analysis, a process to determine whether students were recalling or reconstructing answers. Results suggested that all students increased their rate of correct responding, but few students moved from reconstructive to reproductive processes. Thus, the drill and practice resulted in a faster answer, but it did not produce a tutoring effect to teach immediate recall of math facts. The drill-and-practice application of the CAI did not produce acquisition of new information (knowledge of math facts). The implications, though tentative, are profound. CAP software, as much of it is commonly designed, does not necessarily teach new skills. Therefore, teachers using these forms of CAI with the intent of teaching new basic facts should carefully monitor the learning process. They might be wise to use a more direct form of instruction during the acquisition phase.

\section{PROMISE 7: MICROCOMPUTERS CAN BE PROGRAMMED TO ACT AS INSTRUCTIONAL ENGINEERS}

The term instructional engineer refers to the use of both simple and sophisticated instructional techniques and algorithms that have been demonstrated to be highly effective 
in teaching when used properly (altering the pace of instruction to reflect optimal learning curves for each individual; automatically increasing the requirements for speed of response depending on the student's current level of acquisition of the skill). Although demonstratedly effective, appropriate use of many of the techniques requires intensive training-something that teacher training institutes have not adequately addressed because of overpacked curricula. Thus, many teachers are exposed to only the most rudimentary information about application of principles of learning and teaching (Englert, 1984)-resulting in a form of social invalidity of the more technical procedures. Until problems associated with training and getting teachers to use them are remedied, much of the precise teaching techonology remains on the professorial and rhetorical level.

A promise that offers partial resolution to the social validity issue is that persons with high expertise in instructional engineering can design CAI programs that teachers who have relatively little knowledge of precise teaching procedures can use. Many educators (i.e., Fitzgerald, Fick, \& Milich, 1986; LeBlanc et al., 1986) have noted promises that the microcomputer can be programmed to make and implement instructional decisions based on data reflecting current performance and specific students' individual needs.

For example, Fitzgerald et al. noted that many hyperactive children appear to learn better when allowed to proceed in a self-paced manner (Whalen et al., 1978) and when feedback is continuous as opposed to intermittent or noncontingent (Douglas \& Parry, 1983; Parry \& Douglas, 1983). They noted that microcomputers offer the promise of automatic or selected pacing adjustment and feedback features that make them particularly appropriate for these and other populations with unique learning styles. That type of software will allow delivery of engineered instruction in classrooms that heretofore lacked such precision. A number of studies offers evidence to substantiate this promise (e.g., Collins, Carnine, \& Gersten, in press; Trifiletti, Frith, \& Armstrong, 1984; Fitzgerald et al., 1986). A summary of recent findings related to basic instructional design considerations for $\mathrm{CAI}$ and established principles of effective learning is provided below.

\section{Implicit Versus Explicit Instruction}

Instructional goals of CAI should be purposeful and explicit (e.g., Carlson \& Silverman, 1986; Forman, 1982; Howell \& Kaplan, 1980; LeBlanc et al., 1985; Ragosta, 1982; Trifiletti et al., 1984). Although the effectiveness of
CAI when the instructional goals are implicit (e.g., Factory) remains largely undetermined, much of the CAI with demonstrated effectiveness is based on mastery learning and direct instruction (Collins et al., in press; Woodward et al., 1985).

\section{Frequent, Correct Responses}

Eliciting frequent responses from the learner is more important than providing frequent reinforcement for correct answers (LeBlanc et al, 1985). Practice in making correct responses is a key variable to effective learning. To achieve this, programs should be designed to minimize interference effects and make provisions for appropriately spaced review (Salisbury, 1984). Software that limits the size of the set of initial information to be learned appears to be an effective procedure (Johnson, Carnine, \& Gersten, 1986). Furthermore, software utilizing isolated practice (practicing a single skill in isolation) is effective during initial stages of learning a new skill, but mixed practice (practicing several different skills) may be more effective in the later stages of learning (Resnick, 1981).

\section{Pacing Instruction}

When presenting stimuli based on new information in which a response is required, CAI programs should provide students a brief amount of thinking time until after discrimination has been acquired. In presenting new information, emphasis initially should be on accuracy of responses; later, the program should emphasize both speed and accuracy (e.g., Brophy, 1980; LeBlanc et al., 1985; Torgesen, 1986a, 1986b). Likewise, the pace of the presentation of stimulus materials should be based on learner responding (LeBlanc et al., 1985). For example, several educators (Adams et al., in press; Anderson et al., 1979; Gersten, Carnine, \& Williams, 1982) noted that when student responses are in the $80 \%-90 \%$ accuracy range, emphasis should be placed on making accurate responses. When responses are in the $90 \%$ - 95\% accuracy range, emphasis should be placed on speed of accurate responses. Trifiletti et al. (1984) provided an example of this guideline in the following CAI algorithm for teaching math word problems: (a) If less than $60 \%$ accuracy on math facts, CAI provided tutorial instruction; (b) if $60 \%$ - 89\% accuracy with a speed of less than 40 digits per minute on math facts, computer-assisted drill-and-practice instruction was provided; (c) if accuracy of $\geq 90 \%$ with speed of 
40 digits per minute or more on math facts, word problems were introduced; and (d) the skill was considered mastered when word problem performance was $\geq 80 \%$.

Torgesen (1986b) noted that careful measurement of student response latency should be built into CAI programs so that decisions can be made to determine whether a skill has been sufficiently overlearned. The importance of this feature was underscored by the research of Taymans, Malouf, and Grogan (1985), who found a strong relationship between latency of response during CAI overlearning activities and retention of the material.

Research investigating the type of response mode (e.g., typing answer versus making a one-button response) has not clearly demonstrated the superiority of one mode over another (Cohen \& Torgesen, 1985). The response mode, however, may be closely associated with the nature of the skill being learned (e.g., learning math facts versus spelling words).

\section{Effective Feedback}

In research that assessed learning styles of students via computer applications of stimulus-response tasks, LeBlanc et al. (1985) noted that analyzing students' computer-generated errors led to valuable assessment of their task approach behavior. By analyzing pupils' task approach behaviors related to stimuli presented on a computer monitor, they gathered information regarding which discriminative stimulus elements were consistently present when students responded correctly or incorrectly. This information then was used to successfully identify children who had problems in learning complex discrimination tasks and, at the same time, prescribe learning tasks that followed a predetermined sequence and format (i.e., without the stimuli that were closely associated wih previous error responses).

LeBlanc et al. concluded that when assessment of learning styles is incorporated into instructional software, CAI can become more reactive to varying learner characteristics. When examining the available educational software for exceptional students who display different types of learning characteristics, however, the latter conclusion appears far easier said than done in CAI software programs.

In terms of general guidelines regarding the manner in which feedback should be engineered, LeBlanc et al. noted that feedback for correct versus incorrect responses should not be more reinforcing than that provided for correct responses. Elaborated forms of corrective feedback (e.g., detailed, corrective feedback paired with modeling and prompts to produce correct responses) are more effective than feedback that merely indicates whether a response is correct or incorrect, or by providing the correct answer following an incorrect response (Collins, Carnine, \& Gersten, in press). In addition, following an incorrect response the student should be required to make the correct response (LeBlanc et al., 1985).

\section{Graphics, Sound Effects, and Themes}

Too much reinforcer stimulation, as well as repetitious reinforcement, can interfere with learning (LeBlanc et al., 1985; Chiang et al, 1986). The motivation to engage in academic learning of reluctant students, however, appears to increase when the game-like features are included in the program (Malouf, 1985).

To summarize, the studies reviewed underscore the importance of clarifying intent when decisions are made to employ CAI. If the intent is to review prerequisite skills or to provide automaticity practice of a skill under current instruction, the skill addressed by the CAI should closely adhere to that where practice is needed. In turn, just because a program addresses a skill of interest does not necessarily mean that the program will effectively instruct in a manner that is needed.

Another issue related to intent concerns criticisms of drilland-practice applications. Some educators (e.g., Lepper, 1985) have maintained that CAI should focus more on exploratory and discovery aspects of learning and less on passive drill-and-practice applications. The operative word appears to be intent. If the intent is to promote curiosity and intrinsic interest in a subject, CAI related to inductive learning might be an effective approach. This remains an empirical question. If the intent, however, is to provide large amounts of effective practice on specific skills, select CAP software is demonstrably effective. Thus, the question is not which is the best application of the technology but, rather, given a specified intent, how effective is the microcomputer in addressing it?

\section{PROMISE 8: USE OF WORD PROCESSORS IMPROVES WRITING ABILITY}

Numerous authors have noted many promises associated with using word processors as facilitators of writing ability. 
Frequently featured are the more motivating aspects of writing when using a word processor (the neat, printed copies of work may postively affect students' evaluations of the work)(MacArthur, Graham, \& Skarvold, 1986). Neuman et al. (1985) noted that word processors provide a powerful sense of "authorship" that more conventional techniques cannot offer. Morocco and Neuman (1985) stated the hope that writing on a keyboard will reduce hand cramping. Moreover, revisions are easier; thus, the need for tedious recopying is reduced.

Less optimistically, Degnan (1985) pointed out that because of the memory problems that LD students often experience, many may be precluded from successful application of programs requiring multiple key press or syntax codes for mode crossing; moving between the write, edit, and print modes can be a difficult task for some students to master. Although several educators have mentioned promises associated with using the word processor in the writing process and the teaching of writing (e.g., Bridwell, Nancarrow, \& Ross, 1984; Daiute, 1983; Kane, 1983), only a few studies have systematically investigated its impact.

Results, though preliminary, suggest that the value of word processors, in and of itself, may not be as effective or motivating as initially anticipated. For example, MacArthur et al. compared ll LD students' use of three modes of writing: handwriting, dictation, and word processing. Of the three, dictated stories proved to be the significantly superior mode on a number of variables. For example, dictated stories were longer (median was about 150 words, as compared to a median of about 80 in the other two modes) and had fewer grammatical errors. Notably, no differences were shown between the handwritten stories and those composed on the word processor on a number of variables, including length, quality, structure, vocabulary, mean T-unit length, and mechanical and grammatical errors. On measures of composing rate, dictation again was found superior.

Even though use of the word processor alone may not produce the kind of results initially promised, one should not over-generalize findings to conclude that word processors are not what they have been presumed to be. The medium, paired with specific instruction from the teacher, may yet prove to be a highly valuable instructional tool. But what specific instructional interventions lend themselves effectively to this area is unclear at this time. Some studies have begun to identify some of the problems that mildly handicapped students encounter when using a word processor. Thus, the need for specific instructional skills has begun to be clarified. These are reviewed briefly here.

\section{Cursor Skills}

A naturalistic investigation by MacArthur and Shneiderman (1984) provided evidence of specific difficulties that LD students are likely to experience when learning to use the various features of a word processor. They noted that although students had little difficulty moving the cursor, their movements tended to be inefficient. They tended to use the left and right arrows to move the cursor through several lines of text rather than using the up and down arrows. When inserting a single letter, word, or line within a paragraph, students would first use the space bar to make room for the new material, insert it, and then go back and delete the extra space. They were resistant to change, apparently lacking confidence that the words would move by themselves to make room for the new addition, or they would add the space because without it the stimulus was too visually distracting and confusing.

A second problem observed was that the form of the cursor apparently affected deletion of mistakes. Normally, backspace buttons remove the letter immediately preceding the cursor. When the cursor was a block shape that overlapped the next letter, students tended to mistake the letter to be deleted as the one the cursor was on, rather than in front of. Consequently, students frequently deleted the wrong letters. Fewer deleting mistakes were observed when the cursor was shaped like a capital "I". Cursors of this type tend to fall between letters rather than overlapping the letter (MacArthur, Haynes, \& Malouf 1985; Neuman et al., 1985).

A third problem related to inefficient deleting procedures. If a mistake was several words behind the cursor, the student tended to delete all the way back to it and retype those words after the mistake was corrected, in lieu of moving the cursor to the error for correction.

\section{Keyboarding Skills}

MacArthur, Graham, and Skarvold (1986) found that proficiency in typing was highly correlated with length, quality, and story structure. Thus, this skill appears to be an important variable in the successful application of word processing programs. Also, in a 6-month observation study, Neuman and Morocco (1986) found keyboarding to be a vital skill affecting success in this medium. They observed that teachers tended to use three main approaches to keyboard skill instruction: (a) daily drill and practice with emphasis on hand placement and letter positions; (b) occasional use 
of computer typing games; and (c) no keyboard practice at all. Of these approaches the first appeared to have the most positive results.

Neuman and Morocco concluded that students should be provided with brief (e.g., 5 minutes) and daily keyboarding instruction on the computer (as opposed to a typewriter or cardboard keyboard). Speed should not be emphasized too early, as students are likely to focus on speed rather than accuracy of response. Further, the teacher should provide careful monitoring of student practice. As the authors noted, if practice is provided routinely, students move from "hunting and pecking" to a much faster "pecking" technique. The authors also pointed out that keyboarding instruction is most effective when provided directly on the monitor. This eliminates the need for continuous switching of eye focal points. Ideally, teachers should select typing practice software that accepts only correct responses and that introduces skills gradually while providing ample reinforcement.

\section{Revisions}

An often touted advantage of word processors is that they allow the writer to make quick, easy revisions on a document with a minimal amount of inconvenience. Daiute (1983) explained that this feature allows students to concentrate more on the composition's content, saving the editing process for later. In fact, Neuman et al. (1985) and MacArthur et al. (1986) found that just the opposite tends to occur. Neuman et al. observed that students tended to focus more on the editing process, producing documents that tended to be "technically correct, but shallow in ideas, insight, or the child's own voice" (p. 11).

In an empirical study, MacArthur et al. (1986) verified the observation when they discovered that because of the ease in which revisions can be made, LD students tended to spend more time correcting minor errors during the composing process. They concluded that use of word processors does not necessarily result in greater sophistication of revision strategies, but the word processing may facilitate instruction in revision strategies; students are more willing to make changes when recopying is not necessary.

\section{Composition Skills}

Morocco and Neuman (1985) observed that teachers primarily use three basic approaches to writing instruction when students were using a word processor: skill building, guided writing, and strategy instruction. Skill building involved practice with specific subskills to the writing process (e.g., mechanics, conventions). The authors concluded that the skill-building approach limited the students' involvement in the writing process; thus, the motivating features of word processors (e.g., pride, sense of authorship) were not effectively capitalized upon when the microcomputer was used in this manner.

Guided writing involves the teacher as a guide to assist mildly handicapped students in generating and organizing ideas. The authors reported positive findings when teachers used this approach. The word processor's ability to allow insertion or deletion of text made the composing process particularly amenable to teacher prompts or cues (e.g., "What happened next?"). Thus, the focus tended to remain on content.

Strategy instruction taught students processes for planning, organizing, reviewing and revising. Prewriting planning such as brainstorminig ideas or generating and outlining subtopics on notecards or tree diagrams is a writing process that many educators have advocated (e.g., Moran, Schumaker, \& Vetter, 1981). Some educators have disagreed, stating that this process does not necessarily occur in a linear fashion but, rather, is recursive (Flower \& Hayes, $1980,1981)$. Neuman et al. observed that when teachers encouraged students to apply the strategies while using a word processor, positive results were observed, including what they described as a "high level of involvement and a strong sense of student ownership of the writing" (p. 17), as well as higher levels of independent work when on the computer than other children. What is unclear is the role the word processor played, as opposed to results that might have been observed if some of the students were writing using the more traditional handwriting methods, but using the writing strategies.

Ellis (in preparation) conducted a study that compared writing strategy instruction under various conditions. The study compared students' ability to defend a position using traditional handwriting versus word processing, and word processing paired with an idea processor (e.g., outlining program) under conditions before and after task-specific strategy instruction in defending a position was provided. Results of the pilot study tentatively suggest no differences between handwriting and word processing conditions before strategy instruction, but the word processor paired with an idea processor produced significantly more positive results.

Following the strategy training, students were able to produce noticeably improved documents under all three conditions. The word processor paired with the idea processor 
was again the superior technique. The study suggests that generic strategy instruction (e.g., outlining) is better than no strategy instruction, but it is even more effective when paired with a task-specific strategy (e.g., seven explicit steps to defending a position in writing). The microcomputer's ability to handle both word processing and outlining programs simultaneously appeared to be a key variable.

Morocco and Neuman (1985) concluded that the skill building, as opposed to guided and strategy instruction, had the least positive impact on students' involvement in the writing process and on sense of ownership. Although involvement is arguably a key variable to overall success in learning to write, the study did not clarify where the emphasis of writing instruction should be and at what point writing mechanics and conventions should be emphasized. Though still an empirical question, learning mechanics may be best handled by direct instruction by the teacher, followed by drill-and-practice progams, whereas the word processor would be used for applying mechanics and conventions of print after they had been individually mastered. The word processor also would be used more for developing writing skills in a holistic manner, using guiding and strategic instruction.

In summary, the promise of word processors in relation to improving writing ability is compelling but is yet to be fulfilled. Preliminary studies in this area suggest that using the writing tool does not necessarily improve writing skills, but explorations into effective instruction using this medium have just begun. Although it is unclear whether the problems experienced by mildly handicapped students while learning word processing skills are any different from those of their normal achieving counterparts, specific instruction clearly is needed with this population.

\section{EPILOGUE}

Because educators have only just begun to systematically investigate the effectivenes of microcomputers with mildly handicapped students, the findings reported in this article should be considered tentative; they only begin to address and illustrate effective instructional practices in this area. What these studies do show, however, is that the promise, on the whole, eventually may be fulfilled. The emerging research suggests that microcomputers may be used effectively across a wide variety of instructional applications, including instruction and review of content, fact, skills, strategies, and problem solving.

Moreover, promises related to effective instruction across software applications (e.g., simulations, drill-and-practice, word processing) appear to be on their way to becoming fulfilled, although considerable work in each of these areas is needed before the relative roles of the teacher and the microcomputer are clearly indicated. Blackhurst and $\mathrm{MacAr}$ thur (1985) noted that approximately one-third of the higher education institutions they surveyed reported one or more faculty members engaged in microcomputer research, so the next few years should produce an explosion of information, which should further clarify these issues. In relation to effective instruction and use of microcomputers with mildly handicapped students, the future role of research and the premature locking into practices and beliefs about microcomputer applications are two key areas of concern.

\section{Classroom Computer Use and the Role of Research}

If one assumes that computer use in special education is still in its developing stage, future researchers in this domain should be cognizant of practical applications of the microcomputer and the limitations of most educators' experience with the medium. As in most educational research articles, a discussion of the practical educational implications of a particular study's findings is needed. Unfortunately, many of the studies reviewed for this manuscript lacked this basic component. Moreover, future researchers should take great care in experimental design so that research and interpretation problems common in past special education studies (e.g., sampling and other difficulties found in the early efficacy research of special versus regular education for exceptional students) are not repeated. With the exception of many of the studies reviewed in the manuscript, research in classroom computer applications unfortuately appears to to be repeating some of the special education never-say-die research difficulties.

\section{Premature Locking into Beliefs and Practices}

Despite encouraging results from the studies reviewed in this article, educators concerned with effective instruction when using microcomputers with mildly handicapped students face a major dilemma: Changing basic practices and beliefs is incredibly difficult once they become ingrained in educators' minds. Some less than optimal beliefs aild practices associated with using microcomputers with special populations are well on their way to becoming ingrained. 
The problem is not unlike that faced by the field of learning disabilities. Because so many educators still practice unsubstantiated remediation procedures that became vogue some 20 years ago, the Council for Learning Disabilities recently issued a belated, but profound, call for a moratorium on assessment and remediation practices based on perceptualmotor theories (Leigh, 1986). Lacking empirally based interventions at its inception, educators provided the best that current knowledge had to offer at that time. These popular services resulted in a bandwagon effect. Now, almost a quarter of a century later, LD professionals are struggling to change ingrained beliefs about aptitude/treatment practices in which the emphasis is on student perceptual deficits and not on effective instruction-an area that a wealth of empirical evidence suggests we should attend to more closely (e.g. , Brophy \& Good, 1984; Gersten, Woodward, \& Darch, 1986; Morsink, Soar, Soar, \& Thomas, 1986; Samuels, 1986; Stevens \& Rosenshine, 1981). Current beliefs about and practices using microcomputers suggest that many special educators are creating a new bandwagon-only this time they will be riding with microcomputers in their laps!

Current use of microcomputers and the history of learning disabilities have many parallels. Neither was instigated by professionals but, rather, by parents insisting that schools provide a service. Parent organizations have actively raised money and purchased computers for schools, expecting that teachers do something with them; yet few educators had any real idea what to do. Both have been subject to providing services before an empirical basis for the services had been clearly established, and both have been subjected to promoters who have made exaggerated, unsubstantiated claims and promises that far exceeded what the programs were able to produce (Hofmeister, 1982; LeBlanc et al., 1985; Semmel \& Lieber, 1986; Semmel, Cosden, Semmel, \& Kelemen, 1984; Zientara, 1984).

Further, both the field of learning disabilities and users of educational microcomputers have been subject to simplistic notions regarding what is effective practice. The learning disabilities field has had its share of educators who believe that the key to an individual's success is determining whether the student is a "visual" or "auditory" learner. Likewise, many special educators seem to believe that microcomputers are best used for drill-and-practice, to reward student performance or behavior, or to present games that have no instructional content (LeBlanc et al., 1985).

Since their relative effectiveness appears to be directly related to the extent to which practices draw upon principles of learning and effective instruction (LeBlanc et al., 1985; Ragosta, 1982; Salisbury, 1984; Torgesen, 1986a, 1986b;
Trifiletti, Frith, \& Armstrong, 1984), both fields share one other commonality: They face the task of changing existing practices and beliefs about what is effective instruction. Hopefully, the microcomputer field will not take 20 years to come to grips with this task!

\section{REFERENCES}

Abelson, A., \& di Sessa, A. (1982). Turtle geometry. Cambridge: MIT Press.

Adams, A., Archer, A., Ellis, E.S., \& Moorehead, M.K. (in press). Effective instruction of mildly handicapped adolescents. Reston,VA: Council for Exceptional Children.

Adleman, H.S., \& Taylor, L. (1983). Learning disabilities in perspective. Glenview, IL: Scott, Foresman.

Anderson, L.M., Evertson, C.M., \& Brophy, J.E. (1979). An experimental study of effective teaching in first-grade reading groups. Elementary School Journal, 79, 193-222.

Arms, V.M. (1984). A dyslexic can compose on a computer. Educational Technology, 24 (1).

Beck, I.L., \& Roth, S.F. (1984). Hint and hunt I teacher's manual. Allen, TX: Developmental Learning Materials.

Bell, T.E. (1983). My computer, my teacher. Personal Computing, 7 (6).

Blackhurst, A.E., \& MacArthur, C.S. (1985). Microcomputer use in special education personnel preparation programs. Vienna, VA: Dissemin/Action Products Center.

Bridwell, L.S., Nancarrow, P.R., \& Ross, D. (1984). The writing process and the writing machine: Current research on word processors relevant to the teaching of composition. In R.B. Beach \& L.S. Bridwell (Eds.), New directions in composition research. New York: Guilford Press.

Brophy, J. (1980). Recent research on teaching. East Lansing: Michigan State University.

Brophy, J., \& Good, T. (1984). Teacher behavior and student achievement. In M. Wittrock (Ed.), Third handbook of research on teaching (3rd. ed.). New York: Macmillan.

Budoff, M., Thormann, J., \& Gras, A. (1984). Microcomputers in special education. Cambridge, MA: Brookline Books.

Carlson, S.A., \& Silverman, R. (1986). Microcomputers and computer-assisted instruction in special classrooms: Do we need the teacher? Learning Disability Quarterly, 9 (2), 105-110.

Carman, G.O., \& Kosberg, B. (1982). Educational technology research: Computer technology and the education of emotionally handicapped children. Educational Technology, 22(2), 26-30.

Carnine, D., Lang, D., \& Wong, L. (1984). Health ways. Unpublished computer program, University of Oregon, Eugene.

Chaffin, J.D., Maxwell, B., \& Thompson, B. (1982). ARC-ED curriculum: The application of video game formats to educational software. Exceptional Children 49 (2), 173-178.

Chiang, B. (1986). Initial learning and transfer effects of microcomputer drills on LD students' multiplication skills. Learning Disability Quarterly, 9 (2), 118-123.

Christensen, C.A., \& Gerber, M.M. (1986). Effects of game format in computerized drill and practice on development of automaticity in single digit addition for learning disabled students (Tech. Rep. No. 29). Santa Barbara: University of California, Project TEECh.

Clark, R.E. (1983). Reconsidering research on learning from media. Review of Educational Research, 53 (4), 445-459.

Close, D.W., Irvin, L.K., Taylor, V.E., \& Agosta, J. (1981). Community living skills instruction for mildly retarded persons. Exceptional Education Quarterly, 2, 75-86.

Cohen, A., \& Torgesen, J.K. (1985). Comparison of two versions of a computer program for increasing sight word vocabulary in learning disabled children. Unpublished manuscript, Florida State University. 
Collins, M. (1984). Test of formal logic. Unpublished doctoral dissertation, University of Oregon.

Collins, M., Carnine, D., \& Gersten, R. (in press). Elaborated corrected feedback and the acquisition of reasoning skills. A study of computer assisted instruction. Exceptional Children.

Daiute, C.A. (1983). The computer as stylus and audience. College Composition \& Communication, 34, 134-145.

Deci, E.L. (1975). Intrinsic motivation. New York: Plenum Press.

Degnan, S.C. (1985). Word processing for special education students: Worth the effort. Technological Horizons in Education Journal, 12, 80-82.

Doob, P. (1972). Prospects for simulation gaming in health planning and consumer health education. Reston: VA: ERIC (ED 070 596).

Douglas, V.I., \& Parry, P. (1983). Effects of reward on the delayed reaction time task performance of hyperactive children. Journal of Abnormal Child Psychology, 11, 313-326.

Engelmann, S., \& Carnine, D. (1982). Theory of instruction. New York: Irvington.

Engelmann, S., Carnine, D. \& Collins, M. (1983). DIAL reasoning skills program [computer program]. Eugene, OR: Engelmann-Becker Corp.

Englert, C.S. (1984). Examining effective direct instruction practices in special education settings. Remedial \& Special Education, 5, 38-47.

Ellis, E.S. (in preparation). An examination of the effects of writing strategy instruction using handwriting, word processors, and idea processors with LD adolescents. Columbia, SC: University of South Carolina Program for Exceptional Children.

Ellis, E.S. (1986). The role of motivation and pedagogy on the generalization of cognitive strategy training. Journal of Learning Disabilities, $19,66-70$.

Ellis, E.S., Lenz, B.K., \& Sabornie, E.J. (in press). Generalization and adaptation of learning strategies to natural environments: Part 1. Remedial and Special Education.

Fitzgerald, G., Fick, L., \& Milich, R. (1986). Computer-assisted instruction for students with attentional difficulties. Journal of Learning Disabilities, 19 (6), 376-379.

Flower, L., \& Hayes, J. (1980). The dynamics of composing: Making plans and juggling constraints. In L. Gregg \& E. Steinberg (Eds.), Cognitive processes in writing: An interdisciplinary approach. Hillsdale, NJ: Lawrence Erlbaum.

Flower, L., \& Hayes, J. (1981). Plans that guide the composing process. In C.H. Frederickson and J. Dominic (Eds.), Writing: The nature, development and teaching of written communication. Hillsdale, NJ: Lawrence Erlbaum.

Forman, D. (1982). Review of the literature. Computing Teacher, 9 (5), 37-50.

Furst, M. (1983). Building self-esteem. Academic Therapy, 19 (1).

Gagne, R.M. (1983). Some issues in the psychology of mathematics instruction. Journal for Research in Mathematics Instruction, 14, 7-18.

Garson, J.W. (1983). The case against multiple choice. In D.O. Harper \& J.H. Stewart (Eds.), Run: Computer education. Monterey, CA: Brooks/Cole.

Gersten, R.M., Carnine, D.W., \& Williams, P.B. (1982). Measuring implementation of a structured educational model in an urban school district. Educational Evaluation and Policy Analysis. Eugene: University of Oregon.

Gersten, R., Woodward, J. \& Darch, C. (1986). Direct instruction: A research-based approach to curriculum design and teaching. Exceptional Children, 53 (1), 17-31.

Gleason, M. (1985). A comparison of two CAI approaches in teaching math word problems to handicapped learners. Unpublished doctoral dissertation, University of Oregon.

Good, T.L., \& Grouws, D.A. (1979). The Missouri mathematics effectiveness project. Journal of Educational Psychology, 71, 355-362.

Gray, L. (1984, January). LOGO helps remove children's handicaps. Educational Computer.
Greenblat, C., \& Duke, R. (1975). Gaming simulation: Rationale, design, and application. New York: Halsted.

Guess, E.K. (1981). The future of computer education: Invincible innovation of transitory transformation. Computing Teacher, 9 (1), 39-42.

Hasselbring, T.S. (1986). A chronometric analysis of the effects of computer-based drill and practice in addition and subtraction. Paper presented at the Special Education Technology Conference, Washington, DC.

Haynes, J.A., Kapinus, B.A., Malouf, D.B., \& MacArthur, C.A. (1984). Effect of computer assisted instruction on learning disabled readers' metacognition and learning of new words (Research report \#101). College Park, MD: University of Maryland, Institute for the Study of Exceptional Children and Youth.

Hoffman, R.J. (1982). Microcomputers, evaluation, literacy: Will the teacher survive? Journal of Learning Disabilities, 15 (6), 370-372.

Hofmeister, A.M. (1982). Microcomputers in perspective. Exceptional Children, 49, 115-121.

Hofmeister, A.M. (1984). The special educator in the information age. Peabody Journal of Education, 62 (1), 5-21.

Howell, K., \& Kaplan, J. (1980). Diagnosing basic skills. Columbus, $\mathrm{OH}:$ Merrill.

Johnson, G., Gersten, R., \& Carnine, D. (1986). Effects of instructional design variables on vocabulary acquisition of $L D$ students: A study of computer-assisted instruction. Manuscript submitted for publication.

Jones, K., \& Torgesen, J.K. (1985). An evaluation of the Hint and Hunt I program with learning disabled children. Unpublished manuscript, Florida State University.

Kane, J.H. (1983). Computers for composing (Tech. Rep. No. 21). New York: Bank Street College of Education.

Kleiman, G., Humphrey, M., \& Lindsay, P.H. (1983). Microcomputers and hyperactive children. In D.O. Harper \& J.H. Steward (Eds.), Run: Computer education. Monterey, CA: Brooks/Cole.

Komoski, K.P. (1981). Instructional materials: Products or processes. Journal of Special Education Technology, 4 (3), 36.

Kulik, J.A., Kulik, C.L.C., \& Cohen, P.A. (1980). Effectiveness of computer-based college teaching: A meta-analysis of findings. Review of Educational Research, 50, 525-544.

Larsen, S.C., \& Hammill, D.D. (1976). The test of written spelling. Austin, TX: PRO-ED.

LeBlanc, J.M., Hoko, J.A., Aangeenbrug, M.H., \& Etzel, B.C. (1985). Microcomputers and stimulus control: From the laboratory to the classroom. Journal of Educational Technology, 7(1), 23-30.

Leigh, J. (1986). CLD position statements: Measurement and training of perceptual-motor functions. Learning Disability Quarterly, 9(3), 247.

Lepper, M.R. (1985). Microcomputers in education: Motivational and social issues. American Psychologist, 40(1), 1-18.

Lesgold, A.M. (1983). A rationale for computer-based recording instruction. In A.C. Wilkenson (Ed.), Classroom computers and cognitive science. New York: American Press.

Licht, B.C., \& Kistner, J.A. (1986). Motivational problems of learning-disabled children: Individual differences and their implications for treatment. In J.K.Torgesen and B.Y.L. Wong (Eds.), Psychological and educational perspectives on learning disabilities. New York: Academic Press.

Lieber, J., \& Semmel, M.I. (1986). The effect of group size and configuration on social and performance behaviors of mildly handicapped using microcomputers (Tech. Rep. No. 22). Santa Barbara: University of California, Project TEECh.

MacArthur, C.A., Graham, S., \& Skarvold, J. (1986.) Learning disabled students' composing with three methods: Handwriting, dictation and word processing (Research report \#109). College Park: University of Maryland, Institute for the Study of Exceptional Children and Youth.

MacArthur, C.A., \& Shneiderman, B. (1984). Learning disabled students' difficulties in learning to use a word processor: Implications for instruction and software evaluation. Journal of Learning Disabilities, 19 (4). 
MacArthur, C.A., Haynes, J.A., Malouf, D.B., \& Harris, K. (1986). Computer assisted instruction for learning disabled students: Achievement, engagement, and other factors that influence achievement (Research report \#112). College Park: University of Maryland, Institute for the Study of Exceptional Children and Youth.

Maddux, C.D. (1984). Using microcomputers with the learning disabled: Will the potential be realized? Educational Computer, pp. 31-32.

Magidson, E. (1978), Trends in computer assisted instruction. Educational Technology, 18, 5-8.

Malone, T.W. (1981). Toward a theory of intrinsically motivating instruction. Cognitive Science, 4, 333-369.

Malouf, D.B. (1985). The effects of instructional computer games on continuing student motivation (Research report \#106). College Park: University of Maryland, Institute for the Study of Exceptional Children and Youth.

McDermott, P.A., \& Watkins, M.W. (1983). Computerized vs. conventional remedial instruction for learning-disabled pupils. Journal of Special Education, 17(1), 81-88.

Mokros, J.R., \& Russell, S.J. (1986). Learner-centered software: A survey of microcomputer use with special needs students. Journal of Learning Disabilities, 19(3), 185-190.

Moran, M.R., Schumaker, J.B., \& Vetter, A.F. (1981). Teaching a paragraph organization strategy to learning disabled adolescents (Research report \#54). Lawrence: University of Kansas Institute for Research in Learning Disabilities.

Morocco, C.C., \& Neuman, S.B. (1985). Teaching children to write with computers: Comparing approaches (Tech. Rep. No. 1). Newton, MA: Writing Project, Education Development Center.

Morsink, C.V., Soar, R.S., Soar, R.M., \& Thomas, R. (1986). Research on teaching: Opening the door to special education classrooms. Exceptional Children, 53(1), 32-40.

Neuman, S.B., Morocco, C.C., Bullock, M., Cushman, H., Neale, A., Packard, D., \& Traversi, D. (1985). A model teaching environment for using word processors with LD children. The Writing Project (Tech. Rep. No. 2). Newton, MA: Education Development Center.

Neuman, S.B. \& Morocco, C.C. (1986). Two hands is hard for me: Keyboarding and learning disabled children. Newton, MA: University of Lowell, Education Development Center.

Parry, P., \& Douglas, V.I. (1983). Effects of reinforcement on concept identification in hyperactive children. Journal of Abnormal Child Psychology, 11, 327-340.

Ragosta, M. (1982). Computer-assisted instruction and compensatory education: The ETS/LAUSD study-overview of the final report. Washington, DC: National Institute of Education.

Rashotte, C.A., \& Torgesen, J.K. (1985)). Repeated reading and reading influency in learning disabled children. Reading Research Quarterly, 20, 180-188.

Reith, H. (1986). An analysis of the instructional and contextual variables that influence the efficacy of computer-based instruction for mildly handicapped secondary school students. Paper presented at the Special Education Technology Conference, Washington, DC.

Reith, H., \& Frick, T. (1982). An analysis of academic learning time (ALT) of mildly handicapped students in special education service delivery systems: Initial report on classroom process variables. Bloomington, IN: Project ALT Center for Innovation in Teaching the Handicapped.

Resnick, L.B. (1981). The psychology of drill and practice. In L.B. Resnick \& W.W. Ford, (Eds.), The psychology of mathematics for instruction (pp. 11-37). Hillsdale, NJ: Lawrence Erlbaum.

Romanczyk, R.G. (1986). Direct computer instruction: Issues of assessment, effectiveness, and generalization. Paper presented at Special Education Technology Conference, Washington, DC.

Roth, S.F., \& Beck, I.L. (1984). Research and instructional issues related to the enhancement of children's decoding skills through a microcomputer program. Paper presented at the annual meeting of the American Educational Research Association, New Orleans.

Russell, S.J. (1983, October). LOGO in special education. Classroom Computer Learning, pp. 34-39.

Russell, S.J. (1986). But what are they learning? The dilemma of using microcomputers in special education. Learning Disability Quarterly, $9(2), 100-104$.
Salisbury, D.F. (April, 1984). Cognitive psychology and its implications for designing drill and practice programs for computers. Paper presented at Annual Meetings of the American Educational Research Association, New Orleans.

Samuels, S.J. (1986). Why children fail to learn and what to do about it. Exceptional Children, 53(1), 7-16.

Schiffman, G., Tobin, D., \& Buchanan, B. (1982). Microcomputer instruction for the learning disabled. Journal of Learning Disabilities, 15, 557-559.

Schumaker, J.B., Deshler, D.D., \& Ellis, E.S. (1986). Intervention issues related to the education of LD adolescents. In J.K. Torgesen \& B.Y.K. Wong (Eds.), Psychological and educational perspectives on learning disabilities. Orlando, FL: Academic Press.

Semmel, M.I., \& Lieber, J.A. (1986). Computer applications in instruction. Focus on Exceptional Children, 18(4), 1-12.

Semmel, M.I., Cosden, M.A., Semmel, D.S., \& Kelemen, E. (1984). Training special education personel for effective use of microcomputer technology: Critical needs and directions. Special Services in the Schools, 1(1), 63-82.

Spring, C., \& Perry, L. (in press). Computer assisted instruction in word decoding for educationally handicapped children. Journal of Educational Technology Systems.

Stevens, R., \& Rosenshine, B. (1981). Advances in research on teaching. Exceptional Education Quarterly, 2, 1-9.

Taymans, J.M., Malouf, D.B., \& Grogan, M.M. (1985). An investigation of the relationship between response latency during over-learning and retention for learning disabled students engaged in computer-assisted instruction (Research report \#105). College Park: University of Maryland, Institute for the Study of Exceptional Children and Youth.

Tollefson, N., Tracy, D.B., \& Johnson, E.P. (1982). Self-control training of $L D$ adolescents in a resource room setting (Research report \#69). Lawrence: University of Kansas Institute for Research in Learning Disabilities.

Torgesen, J.K. (1986a). Using computers to help learning disabled children practice reading: A research-based perspective. Learning Disabilities Focus, 1(2), 72-81.

Torgesen, J.K. (1986b). Computer-assisted instruction with learning disabled children. In J.K. Torgesen \& B.Y.L. Wong (Eds.), Psychological and educational perspectives on learning disabilities. Orlando, FL: Academic Press.

Torgesen, J.K., \& Young, K. (1983). Priorities for the use of microcomputers with learning disabled children. Journal of Learning Disabilities, 16, 234-237.

Trifiletti, J.J., Frith, G.H., \& Armstrong, S. (1984). Microcomputers versus resource rooms for learning disabled students: A preliminary investigation of the effects on math skills. Learning Disability Quarterly, 7, 69-76.

Turkel, S.B., \& Podell, D.M. (1984, Summer). Computer-assisted learning for mildly handicapped students. Teaching Exceptional Children, 16(4), 258-262.

Tyler, J.G. (1983). Your prescription for CAI success. Instructional Innovator, $28(2)$

Varnhagen, S., \& Gerber, M.M. (1984). Use of microcomputers for spelling assessment: Reasons to be cautious. Learning Disability Quarterly, $7,226-270$.

Weir, S. (1982). LOGO: A learning environment for the severely handicapped. Journal of Special Education Technology, 5(1).

Whalen, C.K., Collins, B.E., Henker, B., Alkus, S.R., Adams, D., \& Stapp, J. (1978). Behavior observations of hyperactive children and methylphenidate (Ritalin) effects in systematically structured classroom environments: Now you see them, now you don't. Journal of Pediatric Psychology, 3, 177-187.

Wilkenson, A.C. (1983). Learning to read in real time. In A.C. Wilkenson, (Ed.), Classroom computers and cognitive science. New York: Academic Press.

Woodward, J., Carnine, D., \& Collins, M.T. (1986). Closing the performance gap in secondary education. Unpublished manuscript, University of Oregon, Eugene.

Zientara, A. (1983). Microcomputers in early childhood education? Young Children, 38, 61-67.

We would like to express our appreciation to Ellen Peters, Abby Adams, Anita Archer, and Ann Knockendoffel for their ideas relating to the format of this article. In addition, we thank Jill Nyland for her library research assistance. 